This article develops a model of consumption when individuals maximize utility knowing that they will experience varying levels of temptation and willpower over time. Examination of the optimal consumption path reveals that consumers may resist temptation by altering their consumption path. This can generate consumption patterns that mimic time preference even when no underlying time preferences exist. Self-control strategies to increase consumer welfare, such as precommitment and public side bets, are shown to derive directly from the model.

\title{
Temptation, Willpower, and the Problem of Rational Self-Control
}

\author{
MARY E. DEILY \\ Lehigh University \\ W. ROBERT REED \\ University of Oklahoma
}

The problem of self-control, or of managing oneself, is tantalizing for philosophers, psychologists, and economists. The following illustration highlights the salient characteristics of the self-control problem:

An increasingly familiar occurrence for obstetricians is being asked by patients to withhold anesthesia during delivery. The physician often proposes that a facemask be put beside the patient who may inhale nitrous oxide as she needs it. But some determined patients ask that no such opportunity be provided: if gas is available they will use it, and they may want not to be able to.

The request is interesting for decision theory, and raises questions of ethics, policy, and physician responsibility, even if the woman is merely making a mistake-if she simply does not know how painful labor will be... . But some women who make this request have had earlier deliveries during which they demanded anesthesia and received it. They are acquainted with the pain. They

\footnotetext{
Authors' Note: The authors are grateful for helpful comments from Ray Battalio, John Lott, Jr, Thomas Cosimano, S. Charles Maurice, and seminar participants at Texas A\&M University and from two anonymous referees and the editors of this journal.
}

RATIONALITY AND SOCIETY, Vol. 5 No. 4, October 1993 455-472

(C) 1993 Sage Publications, Inc. 
anticipate asking for relief. And they want it withheld when they do. They expect to regret afterwards any recourse to anesthesia. (Schelling 1984a, 1)

Two general classes of explanations have been proposed to explain this phenomenon. The first considers the problem as one of time-inconsistent preferences, resulting either from changing preferences or nonexponential discounting of future utilities (Strotz 1956; Phelps and Pollak 1968; Pollak 1968; Hammond 1976; Simon 1990). ${ }^{1}$ If preferences are time inconsistent, then preference reversals are clearly possible, and long-term consumption plans can be revised as the consumer progresses on his consumption journey. Sophisticated consumers who foresee these events might decide to restrict the consumption choices available to them in the future. According to the theory of time-inconsistent preferences, actions that restrict a consumer's choices, such as removing the option of anesthesia during delivery, can be seen as rational attempts to improve the consumer's utility.

In contrast, other authors have adopted the approach of viewing single individuals as a collection of "selves," each with different tastes or values and with varying degrees of autonomy (Winston 1980; Thaler and Shefrin 1981; Shefrin and Thaler 1988). At any given point in time, an individual has multiple sets of preferences operating simultaneously. Typically, one of the "selves" is assumed to be myopic relative to the other self or selves, creating a coordination problem. In some cases, control of consumption choices can alternate between competing selves (Schelling 1984a, 1984b, 1985). If a change in command is anticipated, the self that is currently in command might choose to constrain the behavior of a future self once that self has taken over control. Although actions that restrict consumption choices can no longer be interpreted as utility improving (it depends on which self one is talking about), these multiple-self explanations do provide a positive theory of the behavioral anomalies associated with self-control. ${ }^{2}$

This article makes three contributions to the self-control literature. First, it argues that both time-inconsistent and multiple-self theories have serious shortcomings. Second, it presents an alternative theory of rational selfcontrol that attempts to address these shortcomings. Finally, it explores the relationship between time preference and temptation.

\section{A CRITIQUE OF PREVIOUS THEORIES}

We can separate the anesthesia paradox into three time periods, with each period characterized by the patient's decision concerning the use of anesthe- 


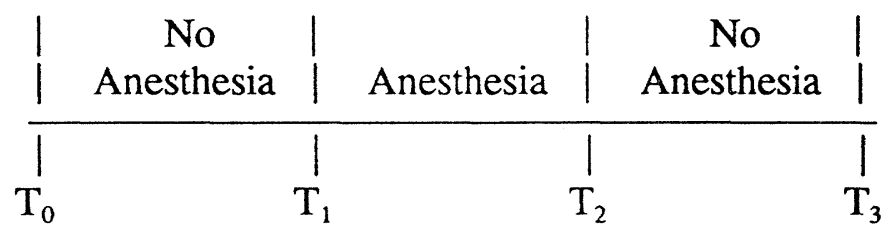

Figure 1: A Representation of the Anesthesia Paradox

sia during delivery (see Figure 1 ). From the vantage point of time $\mathrm{T}_{0}$, the rationally expectant patient weighs out the benefits of an anesthesia-free delivery against the physical pain she knows she will suffer. During the first time period, her calculation of the respective benefits and costs leads her to decide not to use anesthesia during delivery. During the second period, the patient recalculates, and if she has the choice she will decide to use anesthesia. During the third period, her weighting of the (retrospective) costs and benefits change again, and if she used anesthesia during delivery she will regret having done so.

The theory of time-inconsistent preferences states that it is rational (i.e., utility-improving) for a consumer at $\mathrm{T}_{0}$ to choose to make anesthesia unavailable during delivery. We argue that this is a non sequitur. The strategy of restricting future consumption choices cannot be shown to derive from the consumer's underlying maximization problem. The error lies in arbitrarily assigning dominance to the first period's preferences. To see this, consider the following related problem.

Suppose a vegetarian must plan his menu for the next 99 years. Refer to Figure 1 and let $\mathrm{T}_{0}, \mathrm{~T}_{1}, \mathrm{~T}_{2}$, and $\mathrm{T}_{3}$ correspond to $0,33,66$, and 99 years, respectively. A problem arises because he knows (it does not matter how) that during the middle 33 years his preferences will change such that he will prefer a meat diet. At the end of 66 years, the consumer's preferences will revert back to what they were during the first period. Should the vegetarian plan a meat or vegetarian diet during the middle period? The th ught of eating meat during the middle period is abhorrent to the vegetarian from the vantage point of time $\mathrm{T}_{0}$. Further, he knows that once he grows old and enters the last 33-year period he will regret having eaten meat. Knowing this, perhaps he should commit to eating a vegetarian diet during the middle period.

But what if the first period is only 25 years, or 10 , or 1 ? Or the last period. What if the consumer knows that his original vegetarian preferences will only 
last for a day, at which point he will prefer meat for the rest of his life, except for a few minutes before he dies? From his vantage point at $\mathrm{T}_{0}$, he cannot imagine liking meat and so would like to plan a vegetarian diet for the duration of his life. But he knows that if he does he will spend the great portion of his life regretting that choice. Does he restrict his future diet to all vegetarian fare? There is nothing in the theory of time-inconsistent preferences that allows one to answer this question. The strategy of precommitment cannot be demonstrated to follow from the theory.

This shortcoming highlights the advantage of the multiple-self theory. Suppose the self making decisions during the first period is not the same self that will be making decisions in the second period. Because the first self must experience the consequences of the second self's decisions (this is the externality problem identified by Simon 1990), it is clear that the first self might wish to restrict the choices of future selves after he (it?) loses command. Accordingly, the theory of multiple selves provides an internally consistent explanation for the strategy of precommitment.

However, the very feature of changing command, which enables theories of multiple selves to explain behavioral anomalies such as precommitment, raises a number of issues. What allows a future self to wrestle command away from the current self? Is there anything the current self can do to prevent or diminish the probability of this occurring? Furthermore, there is a disturbing asymmetry in the multiple-self theory that calls it into question.

Refer to Figure 1 again and consider the problem of an individual with multiple selves, one of which engages in overeating whenever it is in command. The current nonovereating self is concerned about the health effects of being overweight. He knows that at time $T_{1}$ his overeating other self will take command and want to gorge. To prevent this, he removes all sweet desserts and snacks from his home and workplace. He buys a new wardrobe appropriate for his target weight. He joins Weight Watchers ${ }^{\circledR}$.

Time $T_{1}$ arrives, and his overeating other self takes over. As expected, it goes on an eating binge. However, it does not engage in retaliatory precommitment behavior. It does not move next door to a candy shop in order to thwart the strategy of ridding the home of sweets. It does not replace the new wardrobe with clothes from Fatman's Fashion Boutique. It does not write bad checks to Weight Watchers ${ }^{\circledR}$ so as to preclude future enrollment. Why doesn't it? The theory of multiple selves has little to say with respect to these questions. The next section proposes an alternative theory that attempts to address these shortcomings. 


\section{A MODEL OF RATIONAL SELF-CONTROL}

\section{OVERVIEW}

Consider the following rational, utility-maximizing consumer. $\mathrm{He}$ is a unified personality: His tastes and values are not changing either due to a time preference parameter or due to multiple selves. Instead, internal conflict arises because the individual "is challenged by semi-autonomous strivings. ... The relationship [between the person and the strivings] ... is that of an intentional person confronting causal forces within himself" (Elster 1986, 31). We call these strivings temptation: the attraction experienced by an individual toward a particular object or action giving the promise of immediate pleasure or gain at the expense of future, and perhaps, overall utility. ${ }^{3}$ We assume a person knows that he or she will experience temptation and that sometimes will be able to resist that temptation and sometimes not, depending on the outcome between temptation and willpower. We think of willpower as some level of mental energy that is determined exogenously over time (at least for now) and that may or may not be predictable.

This formulation allows us to retain the sense of a single maximizing decision maker, although one who now faces a more complex planning problem than is usually recognized. We find that a utility-maximizing consumer constrained by temptation and willpower will never plan to give in to temptation, yet sometimes does. Further, although we make only a small beginning in this article, our approach makes it easier to isolate and examine the effects of various types of temptation and, alternatively, some of the devices used to bolster willpower. ${ }^{4}$ Finally, using this framework lets us avoid having to assume positive time preference (Olsen and Bailey 1981) as a parameter, which seems desirable, as people appear to display negative time preference in some circumstances (Loewenstein and Thaler 1989; Loewenstein and Prelac 1991).

\section{THE MODEL ${ }^{5}$}

Consider the case of a shipwrecked consumer. ${ }^{6} \mathrm{He}$ has a fixed supply of potable water, $\mathrm{K}_{0}$ units, and he knows with certainty that he will be rescued in T periods. The consumer's problem is to ration water consumption over $\mathrm{T}$ units of time given a fixed stock of the consumption good at time $t=0$. If the consumer could formulate and implement a consumption plan without feeling temptation, then his problem would be 


$$
\begin{gathered}
\max \int_{0}^{T} u[c(t)] d t, \text { subject to }{ }^{7} \\
\stackrel{\cdot}{K}(t)=-c(t) \\
K(0)=K_{0} \\
K(T) \geq 0 .
\end{gathered}
$$

Given standard assumptions on the utility function, such as diminishing marginal utility, the solution to this optimal control problem consists of consuming the same amount of water each period $\left(\mathrm{K}_{0} / \mathrm{T}\right.$ units per period), with the supply of water being exhausted just prior to being rescued. ${ }^{8}$

Suppose our consumer knows, however, that there will be a time when he will be tempted to drink more than his allotted ration of water. We propose that a key determinant of his feeling the temptation to drink more than he planned will be the difference between his planned consumption and his most tempting alternative at that time. That is, it is not just the level of consumption but the availability of alternatives that matters: Common experience supports the idea that the temptation to cheat on one's diet is greater when one knows that there is a gallon of cookies and cream ice cream in the kitchen freezer.

Formally, we model this feeling as $F(t)=f\left(c^{a}(t)-c^{p}(t)\right)$, where $c^{p}(t)$ is the planned consumption choice at time $\mathrm{t}$, and $\mathrm{c}^{\mathrm{a}}(\mathrm{t})$ is the most tempting alternative choice. Because our consumer's utility function is a simple function of the amount of consumption, the most tempting alternative for our consumer at any time $t$ is to drink all of the remaining water stock. That is,

$$
F(t)=f\left(K(t)-c^{p}(t)\right) .^{9}
$$

Thus our consumer now must choose between a long-run consumption plan that optimizes overall utility and the tempting alternative choice of consuming all the water immediately. Resolution of this choice at time $t$ will depend on a function $\mathrm{W}(\mathrm{t})$, which we use to represent the consumer's willpower at time $t$. We assume $\mathrm{W}(\mathrm{t})>0$, where $0 \leq \mathrm{t} \leq \mathrm{T}$. $\mathrm{W}(\mathrm{t})$ represents the consumer's ability to resist temptation and stay on the planned consumption path. If $W(t) \geq F\left(K, c^{p}\right)$, then the consumer sticks to his plan and consumes $c^{\mathrm{p}}(\mathrm{t})$. If, however, $\mathrm{W}(\mathrm{t})<\mathrm{F}\left(\mathrm{K}, \mathrm{c}^{\mathrm{p}}\right)$, then temptation is too strong and the consumer consumes $\mathrm{K}(\mathrm{t})$, the remaining stock of water available at time $\mathrm{t}^{10}$

The consumer's problem, then, is to allocate his consumption among the different periods, knowing that his total consumption cannot exceed the 
available stock and that the consumption planned for each period will be affected by the net impact of willpower versus temptation.

\section{OPTIMAL CONSUMPTION IN THE CASE OF CERTAIN WILLPOWER}

We first assume that the consumer knows the amount of willpower, $\mathrm{W}(\mathrm{t})$, that he will have at each point in time. The consumer's maximization problem becomes

$$
\begin{aligned}
& \max \int_{0}^{T} u[c(t)] d t \text {, subject to } \\
& \stackrel{\bullet}{\mathrm{K}}(\mathrm{t})=-\mathrm{c}(\mathrm{t}) \text {; } \\
& \mathrm{K}(0)=\mathrm{K}_{0} \text {; } \\
& \mathrm{K}(\mathrm{T}) \geq 0 ; \\
& W(t) \geq F[K(t), c(t)] ;
\end{aligned}
$$

where the arguments of the temptation function are now identified as the state, $K(t)$, and control, $c(t)$, variables. ${ }^{11}$ The Lagrangean expression for this problem is given by

$$
\mathrm{L}=\int_{0}^{\mathrm{T}}\{\mathrm{u}[\mathrm{c}(\mathrm{t})]+\lambda(\mathrm{t}) \dot{\mathrm{K}}(\mathrm{t})+\dot{\lambda}(\mathrm{t}) \mathrm{K}(\mathrm{t})+\rho[\mathrm{W}(\mathrm{t})-\mathrm{F}(\mathrm{K}(\mathrm{t}), \mathrm{c}(\mathrm{t}))]\} \mathrm{dt}+\lambda(0) \mathrm{K}(0)-\lambda(\mathrm{T}) \mathrm{K}(\mathrm{T})
$$

A number of interesting results are generated by this model. First, if willpower and temptation are perfectly anticipated, our shipwrecked consumer will plan a consumption path that will allow him to ration his water until he is rescued, without ever yielding to temptation. This follows directly from the assumption of diminishing marginal utility: Consumer welfare is always improved by balancing consumption across time periods. A consumption plan that calls for consuming all of the water stock before being rescued is always dominated by one that saves some water for later consumption. Note, though, that this result requires that the consumer perfectly predict how much willpower he will have at all points in the future.

Second, the model generates our first example of strategic self-control behavior, a behavior we call "defensive consumption." To see this, note that the first-order conditions to the Lagrangean expression above are

$$
\partial \mathrm{L} / \mathrm{c}=(\partial \mathrm{u} / \partial \mathrm{c})-\lambda-\rho(\partial \mathrm{F} / \partial \mathrm{c})=0
$$


and

$$
\partial \mathrm{L} / \partial \mathrm{K}=\dot{\lambda}-\rho(\partial \mathrm{F} / \partial \mathrm{K})=0 .
$$

The transition and transversality equations are given by

$$
\dot{K}(t)=-c(t) \text {; }
$$

and

$$
\partial \mathrm{L} \partial \mathrm{K}(\mathrm{T})=-\lambda(\mathrm{T})=0 .
$$

Two cases are distinguishable.

\section{Case 1}

The first case arises whenever the willpower constraint is not binding; implying that $\rho$, the shadow value of the constraint, is zero. In this case, no self-control problem arises. With $\rho=0$, Equations 4.1 and 4.2 can be used to derive the following relationships:

$$
\begin{gathered}
\partial u / \partial c=\lambda, \\
\dot{\lambda}=0 ;
\end{gathered}
$$

and

$$
\dot{\mathrm{c}}=\dot{\lambda}\left(\partial^{2} \mathrm{u} / \partial \mathrm{c}^{2}\right)^{-1}=0 .
$$

Equation 5.3 makes it clear that consumption remains constant within intervals when willpower is strictly greater than temptation. Indeed, if willpower exceeds temptation in all time periods, then the solution to the consumption problem reverts to $\mathrm{c}=\mathrm{K}_{0} / \mathrm{T}$, the solution to the shipwrecked consumer's problem with no temptation. ${ }^{12}$ Furthermore, Equation 5.1 implies that consumption will be the same across all intervals where willpower exceeds temptation. Call this level of consumption $\overline{\mathrm{c}}$.

Note that temptation is always decreasing during those intervals where willpower exceeds temptation. This is because the water stock is getting smaller while the level of consumption remains constant. A formal demonstration of this proceeds by differentiating the temptation function, substituting Equation 4.3, and noting that $\mathrm{c}=0$ and $\partial \mathrm{F} / \partial \mathrm{K}>0$ yield

$$
\dot{\mathrm{F}}=-(\partial \mathrm{F} / \partial \mathrm{K}) \mathrm{c}+(\partial \mathrm{F} / \partial \mathrm{c}) \dot{\mathrm{c}}=-(\partial \mathrm{F} / \partial \mathrm{K}) \mathrm{c}<0 .
$$

This last result will prove useful below. 


\section{Case 2}

The second case arises whenever the willpower constraint is binding, so that $\rho>0$ and $\mathrm{W}(\mathrm{t})=\mathrm{F}\left[\mathrm{K}^{*}(\mathrm{t}), \mathrm{c}^{*}(\mathrm{t})\right]$. Differentiation of the binding constraint and substitution of Equations 5.4 and 4.3 yield

$$
\dot{\mathrm{W}}=\dot{\mathrm{F}}=-(\partial \mathrm{F} / \partial \mathrm{K}) \mathrm{c}+(\partial \mathrm{F} / \partial \mathrm{c}) \dot{\mathrm{c}} \text {. }
$$

Solving for $\stackrel{\bullet}{c}$ yelds

$$
\dot{\mathrm{c}}=[\dot{\mathrm{W}}+(\partial \mathrm{F} / \partial \mathrm{K}) \mathrm{c}] /(\partial \mathrm{F} / \partial \mathrm{c}) .
$$

Because the feeling of temptation is assumed to be decreasing in current consumption, $(\partial \mathrm{F} / \partial \mathrm{c}<0)$, it follows that

$$
\begin{aligned}
& \dot{\mathrm{c}}>0 \text { if } \dot{\mathrm{W}}<-(\partial \mathrm{F} / \partial \mathrm{K}) \mathrm{c} \\
& \dot{\mathrm{c}}=0 \text { if } \dot{\mathrm{W}}=-(\partial \mathrm{F} / \partial \mathrm{K}) \mathrm{c} \\
& \dot{\mathrm{c}}<0 \text { if } \dot{\mathrm{W}}>-(\partial \mathrm{F} / \partial \mathrm{K}) \mathrm{c} .
\end{aligned}
$$

In this situation, the consumer correctly anticipates that his willpower will fall short of temptation, and he engages in "defensive consumption." Suppose that initially the consumer's willpower exceeds his level of temptation. Let $\tau$ identify the first instant of time when the willpower constraint becomes binding. If willpower equals temptation at time $\tau$, then it must be the case that willpower was decreasing faster than temptation just prior to $\tau$; that is, $\grave{W}(t)<\dot{F}(t)=-(\partial F / \partial K) \bar{c}$ for $t$ right before $\tau$. If willpower continues to decline at a faster rate than temptation given constant consumption $\bar{c}$, then the only way that the consumer can satisfy the willpower constraint is to increase consumption. This is the sense of Equation 6.3a.

Figure 2 illustrates this strategy. In Regions 1 and 4 willpower exceeds the temptation to consume the available capital. In these regions the consumption rate is constant at $\bar{c}$. In Regions 2 and 3, however, the willpower constraint is binding, and the consumer will choose to increase his rate of consumption immediately so as to counteract the reduction in his willpower by reducing temptation to tolerable levels. As willpower increases again, consumption falls back to its original level.

Although the specific behavior of this defensive consumption in the shipwrecked consumer's case is somewhat idiosyncratic, it does represent what we believe is a common self-control strategy. An example of this type of behavior might be use of the snooze button on clock radios: By hitting this button, a person can sleep an extra 10 minutes without giving into the 

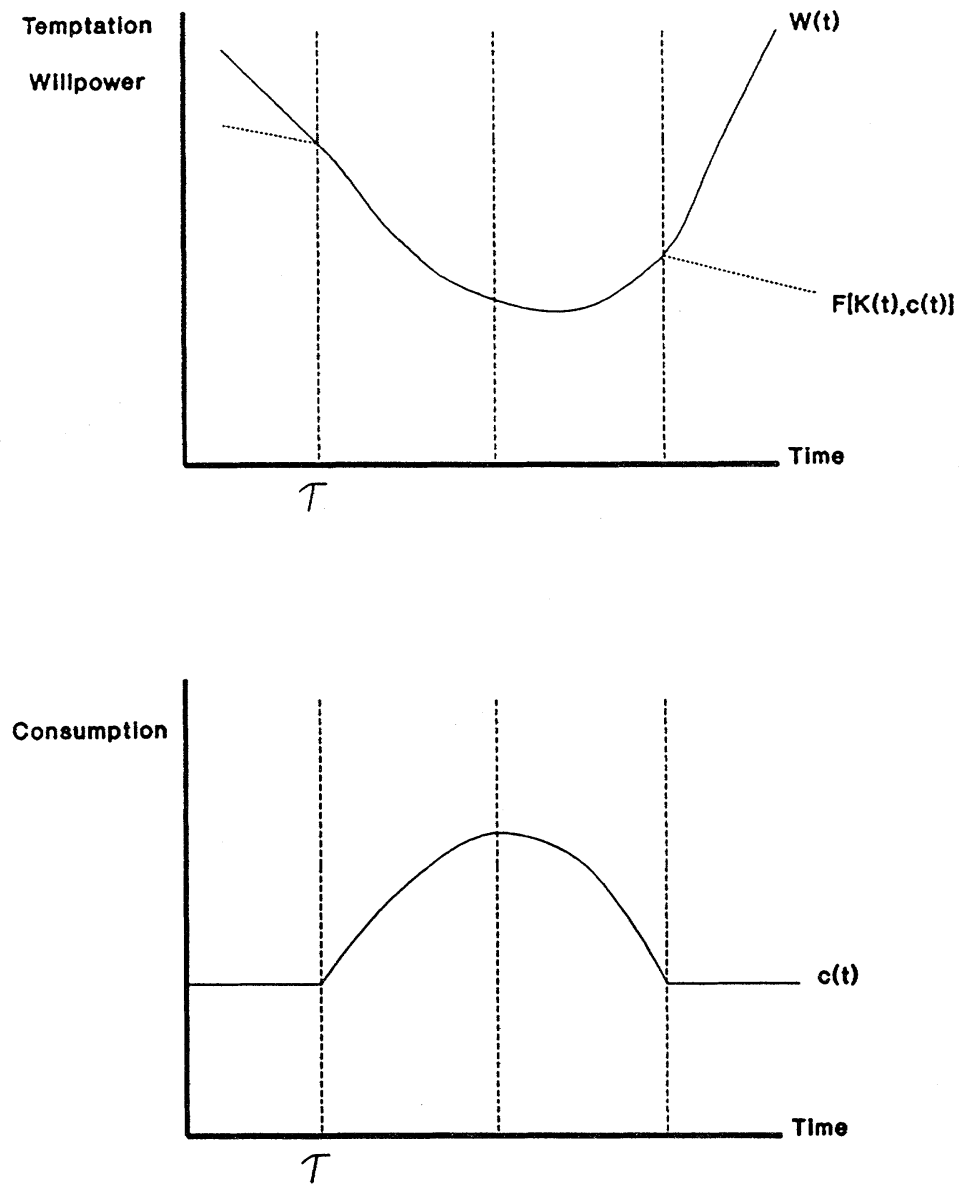

Figure 2: Time Paths for W(t), F(t), and c(t)

temptation to turn the alarm off entirely. Another example are the desserts sold by Weight Watchers ${ }^{\circledR}$ : "diet" brownies, strawberry shortcake, fudge cake, chocolate mousse, and so on allow a person to have a sweet after dinner without completely "falling off the wagon." Finally, a number of antismoking programs are based on a gradual reduction in the amount of cigarettes smoked per day (or the concentration of nicotine inhaled by the smoker). The level of temptation generated by a cold-turkey withdrawal from smoking might exceed the consumer's capacity to resist. 
In summary, although our shipwrecked consumer never yields to temptation, he must adjust his consumption path to accommodate those instances when his willpower would otherwise be insufficient to withstand his feelings of temptation. Using this tactic of "defensive consumption," the consumer reaches higher levels of utility than if he yielded completely to temptation, although not so high as he would if he felt no temptation at all. The resulting consumption path is thus second-best only relative to the path the consumer would follow if temptation did not exist.

\section{OPTIMAL CONSUMPTION IN THE CASE OF UNCERTAIN WILLPOWER}

In the model above, the shipwrecked consumer always sticks to his planned consumption path, despite the existence of temptation. This result depends on the consumer knowing the path his willpower will take. If he is uncertain about the path of his future willpower, then his optimal consumption path will allow a positive probability of yielding to temptation. ${ }^{13}$

This more complicated optimization problem can be solved by thinking of the consumer maximizing utility over a set of discrete time periods. Each period, the consumer receives a new value of willpower drawn from some known distribution function. However, the shipwrecked consumer must plan his drinking schedule before he knows his future willpower realizations.

Consider the marginal benefits and costs associated with planning to consume an additional unit of water during one of the earlier time periods. The benefit of consuming more water sooner, in addition to the extra utility from that consumption, is the reduced risk of yielding to temptation and consuming the entire water stock, leaving nothing for future periods. The cost is the marginal loss in reduced future water consumption.

It is obvious that the shipwrecked consumer will never plan to consume the entire water supply prior to being rescued for the very same reason that he would not want to do so in the certainty case. At the same time, however, he may allow some positive probability of yielding to temptation, given a sufficiently "bad" (low) draw from the willpower distribution. Increasing current water consumption to the point of eliminating all likelihood of succumbing to temptation might be too costly (in terms of orgone future consumption) to warrant the elimination of all risk.

\section{WELFARE-IMPROVING SELF-CONTROL STRATEGIES: PRECOMMITMENT AND PUBLIC SIDE BETS}

We have thus far considered the problem of self-control without allowing the consumer to use strategies for enforcing his consumption plans, aside 
from varying his own consumption. Such strategies generally fall into one of two categories: precommitment or public side bets. In this section, we identify the common logic underlying these two strategies and demonstrate that they are consistent with standard notions of rationality; that is, they are utility-increasing.

Precommitment involves restricting one's future consumption alternatives. ${ }^{14}$ Examples include committing oneself to a fat farm, giving one's keys to another so that one precludes the option of driving home drunk later in the evening, and the anesthesia example cited earlier. Returning to the shipwrecked consumer problem, let $\kappa(t)$ be the best alternative consumption choice (the temptation) at time $t$ given the precommitment program, where $\kappa(t)<K(t)$. Let $\zeta(t)$ be the cost of implementing the precommitment program at time $t$. A precommitment program is then defined by the pair $\{\zeta(t), \kappa(t)\}$.

Precommitment increases consumer welfare because it allows the consumer to enjoy a given level of consumption while experiencing lower temptation. To see this more clearly, assume that the precommitment program costs nothing to implement; that is, $\zeta(t)=0$ for all $t$. With precommitment, $\mathrm{F}[\kappa(\mathrm{t}), \mathrm{c}(\mathrm{t})]<\mathrm{F}[\mathrm{K}(\mathrm{t}), \mathrm{c}(\mathrm{t})]$ for all levels of consumption, $\mathrm{c}(\mathrm{t})$, because $\kappa(\mathrm{t})<$ $\mathrm{K}(\mathrm{t})$. Because a reduction in temptation is tantamount to having greater willpower, it is obvious that the shipwrecked consumer's utility will always be improved so long as $\kappa(t)$ is not less than the planned level of water consumption for that period. The restriction of alternatives provides the rational consumer an opportunity to improve his well-being by enabling him to stick to a consumption level that previously lay outside his willpower capabilities, as long as the costs of implementation are not prohibitively large.

The other strategy, public side bets, represents a self-control mechanism in which the consumer is required to forfeit something if he makes a wrong choice. A great many behaviors fit in this category, including leaving one's credit cards at home before embarking on a shopping trip, placing the alarm clock across the room, or agreeing to present a (currently unwritten) paper at a future academic conference. Institutions such as Alcoholics Anonymous, Weight Watchers®, and obligatory confession, which involve public acknowledgment of one's failures, are of this ilk: The public confession imposes a penalty on the consumer that makes the relevant temptation less attractive.

Define a public side bet program by the pair $\{\zeta(t), \beta(t)\}$, where $\zeta(t)$ is the cost of implementing the program at time $t$, as defined above, and $\beta(t)$ is the penalty (posted bond) that the consumer incurs (forfeits) if he consumes other than the planned consumption choice. Under a public side bet program, if the consumer yields to consumption, he gains only $K(t)-\beta(t)$ rather than $K(t)$ 
(i.e., having walked across the room to turn off the alarm clock, he has to walk back to bed if he chooses to sleep in; he has to confess to taking a drink, etc.).

Once again, assume that this self-control strategy is costless to implement. Then the temptation that the consumer experiences in any given period is given by $F[K(t)-\beta(t), c(t)]$. Because $F[K(t)-\beta(t), c(t)]<F[K(t), c(t)]$ for all levels of consumption, $c(t)$, public side bets can increase consumer welfare for the same reason that precommitments can: They reduce temptation for the consumer by reducing the value of his most tempting alternative. In the context of the shipwrecked consumer, the two self-control strategies are equivalent. For any precommitment program $\{\zeta(t), \kappa(t)\}$, there is a public side bet program $\{\zeta(t), \beta(t)\}, \beta(t)=K(t)-\kappa(t)$, that yields identical outcomes.

In summary, both strategies work by making alternative consumption possibilities less attractive, thus reducing the probability that the consumer will succumb to temptation. In so doing, they allow the consumer to follow a consumption path that yields greater utility than he could otherwise achieve. The crucial element here is the existence of temptation and the recognition that temptation is a function not only of the goods consumed but also of the goods available to be consumed. Accordingly, actions that restrict the consumer's choice set, such as precommitment and public side bet strategies, are easily seen to be perfectly rational consumption behaviors.

\section{THE RELATIONSHIP BETWEEN TEMPTATION AND TIME PREFERENCE}

It is common for theories of time-inconsistent preferences to assume a particular discount rate structure to explain how preference reversals can arise. We have already demonstrated that these ad hoc assumptions are not necessary to explain preference reversals. In this section, we show that the existence of time preference arises naturally in a model incorporating temptation because consumers shift consumption toward those time periods where either willpower is lowest or temptation is highest. In the model of the shipwrecked consumer, temptation is greatest in early periods when the available stock of water is large. As a result, the consumer shifts consumption forward, thus generating a consumption pattern that mimics an inherent preference of current over future consumption.

Thinking about discounting in this way allows one to consider some other issues. Many authors have related the ability to save and invest in either human or physical capital to a person's personal discount rate, the magnitude 


\section{Probability density}

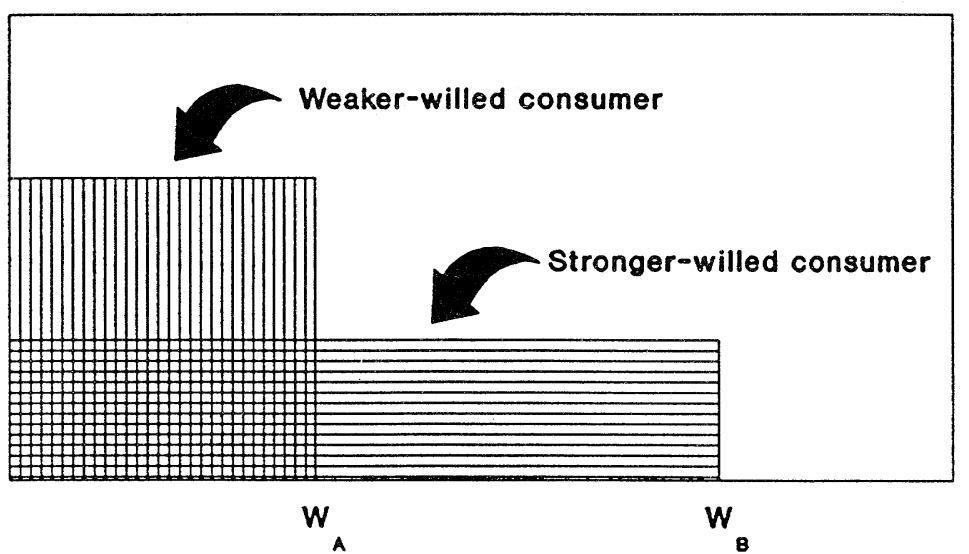

Figure 3: Willpower Distributions

of which is a learned behavior determined in part by a person's social class (Fisher 1930; Strotz 1956; Banfield 1974). Our model shows that the relationship between a person's "weakness of will," as defined below, and the size of that person's time discount factor, is complex.

Consider two consumers, identical in every respect except for their distributions of willpower. Consumer A draws random values of willpower from a uniform distribution function, $\Omega_{\mathrm{A}}\left(\bullet^{\circ}\right.$, where $\Omega_{\mathrm{A}}$ has support on $\{0$, $\mathrm{W}_{\mathrm{A}}$ ). Consumer $\mathrm{B}$ draws new values of willpower from a uniform distribution function $\Omega_{\mathrm{B}}(\bullet)$, where $\Omega_{\mathrm{B}}$ has support $\left(0, \mathrm{~W}_{\mathrm{B}}\right)$. These two distributions are represented in Figure 3. We then say that Consumer $A$ is weaker willed than consumer $\mathrm{B}$ if $\mathrm{W}_{\mathrm{A}}<\mathrm{W}_{\mathrm{B}}$.

Given these specifications, one cannot say whether weaker-willed Consumer $A$ will demonstrate a higher or lower rate of time preference than will stronger-willed Consumer B. Consumer A is more likely to fall into temptation during the current period: The value of a marginal increase in current consumption is thus greater, making larger consumption in the current period more likely. However, he is also more likely to fall into temptation during all future periods, which decreases the opportunity cost of avoiding temptation in the current period. Depending on the resolution of these two effects, the current consumption of Consumer $A$ and the associated rate of time discounting may or may not be higher than that of Consumer B. 


\section{CONCLUSION}

The problem of self-control exerts a continuing fascination for students of human behavior. Although an extensive literature on this subject exists, much of it models the problem as one of changing tastes over time or as a struggle between alternative sets of preferences (selves). Instead, this article has attempted to formally incorporate the importance of environment on individual consumption behavior: It is harder to decide to get dressed and go to work in the morning when one is still in - as opposed to out of-bed. It is harder to resist dessert after it has been placed on the table. Returning to the anesthesia paradox presented in the beginning of this article, it is harder to choose a drug-free labor and delivery when anesthesia is readily available. Accordingly, this analysis introduces the notion of temptation, which is posited to be a function of the alternatives available in one's immediate consumption environment. There are a number of advantages of adopting this approach to the subject.

First, unlike the multiple-self theories, it provides an explanation of preference reversals that maintains the unity of the individual decision maker. The woman who reneges on her decision to forgo anesthesia during delivery is the same self who earlier chose not to use anesthesia. It is just that the temptation to deviate from her plan of no anesthesia is greatest during delivery.

Second, unlike theories of time-inconsistent preferences, it demonstrates that self-control strategies such as precommitment and public side bets are rational; that is, they are utility-improving. The woman who precommits to having anesthesia made unavailable to her is like the dieter who excuses himself from the table before dessert is served. Both are reducing the temptations associated with their respective consumption choices. If one thinks of temptation as a tax on a particular consumption bundle, then the rationality of choosing an environment with fewer temptations is obvious.

Third, it predicts a form of self-control behavior not previously identified in the self-control literature-“defensive consumption." Defensive consumption is the behavior of deviating from one's ideal consumption plan to reduce the probability of succumbing to temptation. For example, many dieters choose to lose weight gradually, maintaining a consumption level higher than the level that would be ideal for attaining their target weight most quickly. Diet experts say that this increases the likelihood that dieters will successfully achieve and maintain their desired weight. This is consistent with the notion of eating enough to keep the temptation to cheat on one's diet at a manageable level. 
Finally, it provides a utility-based derivation of time preferences. Even if the consumer values future and current consumption equally, consumption patterns consistent with time preferences can arise as the consumer allocates consumption to deal with changes in temptation and willpower over time.

We believe that the formal incorporation of temptation and willpower provides a useful handle for understanding the mechanisms that people use to control themselves. This article makes only a small beginning toward this goal. Further study of both the determinants of temptation and willpower and the devices that individuals can employ to reduce temptation and/or increase willpower seems warranted. We hope that this study stimulates further research in this direction.

\section{NOTES}

1. The existence and the nature of time preference are crucial in discounting models. If people discount utility exponentially, then their preferences are consistent and self-control is not a problem. If the discounting function is more concave than an exponential function, then preference reversals might occur (Ainslie 1975, 1986).

2. See Elster (1986) for a short overview of these and other types of multiple-self models.

3. We do not consider temptation to represent an alternative "self" with a separate preference and value structure. The model of a person as a collection of preferences and values appears more useful for explaining conflict between an individual's self-interest and a group interest, as in Margolis (1982). Other authors are working to reconcile Homo economicus, whose behavior is driven by rational self-interest, to Homo sociologicus, whose behavior is driven by social norms, by suggesting that there is, at some fundamental level, a rational basis for adhering to social norms (e.g., Sen 1985; Frank 1988; Sugden 1989; but see also Elster 1989a, 1989b).

4. For example, one could allow temptation to have different time profiles (e.g., daily vs. sudden and unexpected) (see Schelling $1984 \mathrm{~b}$ for a list of various characteristics of different types of temptation). Also, one could model willpower explicitly, perhaps as a "muscle" whose strength increases with use, to incorporate Ainslie's $(1975,1986)$ insight that current decisions to resist temptation are affected by a consumer's concern about his future decisions. Or, one might begin specifying mathematically such concepts as bright lines, which appear to affect a person's willpower (see Schelling 1984b, 1985 and Ainslie 1986 for some discussion of techniques of self-control).

5. Shefrin and Thaler (1988) develop a model of willpower that is similar to the model presented here. An important difference is that they retain the multiple-self framework, assuming separate "planner" and "doer" selves.

6. The following problem is inspired by the following anecdote: "Shipwrecked people and others restricted to a limited amount of drinking water find it very difficult to ration themselves in order to make their drinking water last for a maximum or desired number of days. The pleasure of quenching a thirst seems so great that some people cannot stop drinking even though they know that doing so will cost them a greater thirst in the future, or may even cost them their chance of survival" (Scitovsky 1976, 64).

7. Note that the consumer's utility function does not assume time preference. A discussion of the relationship between time preference and the ideas of this article is presented in a later section. 
8. A proof of this and other results presented in this article is contained in a mathematical appendix that can be obtained from the authors.

9. With this specification, the consumer feels the strongest temptation at the beginning of his ordeal when the amount of available water is large relative to his planned consumption. Alternative formulations might have his temptation increase over time with his cumulative water deprivation. See Schelling (1986) and Ainslie (1986) for some discussion of the various ways in which temptation and satiation might be related.

10. This notion of temptation being too strong is meant to correspond to the idea of "psychological impossibility," as suggested by Hare (1971). For replies to this notion, read Lukes (1971) and Matthews (1971) in the same volume.

11. The careful reader will note that this formulation of the problem assumes that it is never optimal to give in to temptation: admissible $c(t)$ require that $W(t) \geq F[K(t), c(t)]$. In fact, it is easily demonstrated that it is never optimal for the consumer to plan to give in to temptation: That is, the optimal consumption path rules out the possibility that $c(t)$ equals $K(t)$ (except at $\mathrm{t}=\mathrm{T}$ ). Also note that temptation does not directly cause disutility in the formulations of Equations 3 and 4 . The main results of our analysis would be unaffected if one allowed temptation itself to cause disutility. We adopt this specification for reasons of mathematical tractability.

12. An example of this situation might be the successful dieter: persons who lose and keep off weight. They might still feel temptation to overeat, but their willpower is strong enough to prevent giving in to the impulse.

13. We could have assumed that the consumer was uncertain about the path of temptation instead of willpower, or uncertain about the future levels of both, without changing our basic results.

14. Elster (1979) provides a number of criteria toward a definition of precommitment, or what he terms binding oneself. One necessary requirement is that "to bind oneself is to carry out a certain decision at time $t_{1}$ in order to increase the probability that one will carry out another decision at time $t_{2}$ " (p. 39).

\section{REFERENCES}

Ainslie, George. 1975. Specious reward: A behavioral theory of impulsiveness and impulse control. Psychological Bulletin 82 (4): 463-96.

1986. Beyond microeconomics: Conflict among interests in a multiple self as a determinant of value. In The multiple self, edited by J. Elster. Cambridge: Cambridge University Press.

Banfield, Edward C. 1974. The unheavenly city revisited. Boston: Little, Brown.

Elster, Jon. 1979. Ulysses and the Sirens. Cambridge: Cambridge University Press.

1986. The multiple self. Cambridge: Cambridge University Press.
.1989a. Social norms and economic theory. Journal of Economic Perspectives 3 (4): 99-117.

1989b. The cement of society. Cambridge: Cambridge University Press.

Fisher, Irving. 1930. The theory of interest. London: Macmillan.

Frank, Robert H. 1988. Passions within reason: The strategic role of the emotions. New York: Norton.

Hammond, Peter J. 1976. Changing tastes and coherent dynamic choice. Review of Economic Studies 43:159-73. 
Hare, R. M. 1971. Backsliding. In Weakness of will, edited by Geoffrey Mortimore. London: Macmillan.

Loewenstein, George, and Drazen Prelac. 1991. Negative time preference. American Economic Review Papers and Proceedings 81 (May): 347-52.

Loewenstein, George, and Richard H. Thaler. 1989. Anomalies: Intertemporal choice. Journal of Economic Perspectives 3 (4): 181-93.

Lukes, Steven. 1971. Moral weakness. In Weakness of will, edited by Geoffrey Mortimore. London: Macmillan.

Margolis, Howard. 1982. Selfishness, altruism, and rationality: A theory of social choice. Cambridge: Cambridge University Press.

Matthews, Gwynneth. 1971. Weakness of will. In Weakness of will, edited by Geoffrey Mortimore. London: Macmillan.

Olsen, Mancur, and Martin J. Bailey. 1981. Positive time preference. Journal of Political Economy 89 (1): 1-25.

Phelps, E. S., and Robert A. Pollak. 1968. On second-best national saving and game-theoretic equilibrium growth. Review of Economic Studies 35:185-99.

Pollak, Robert A. 1968. Consistent planning. Review of Economic Studies 35:201-8.

Schelling, Thomas C. 1984a. Self-command in practice, in policy, and in a theory of rational choice. American Economic Review Papers and Proceedings 74 (2): 1-11.

1984b. The intimate contest for self-command. In Choice and consequence. Cambridge, MA: Harvard University Press.

. 1985. Enforcing rules on oneself. Journal of Law, Economics, and Organization 1 (2): 357-74.

1986. The mind as a consuming organ. In The multiple self, edited by J. Elster. Cambridge: Cambridge University Press.

Scitovsky, Tibor. 1976. The joyless economy. New York: Oxford University Press.

Sen, Amartya. 1985. Goals, commitment, and identity. Journal of Law, Economics, and Organization 1 (2): 341-55.

Shefrin, Hersh M., and Richard H. Thaler. 1988. The behavioral life cycle hypothesis. Economic Inquiry 26 (October): 609-43.

Simon, Julian L. 1990. The theory of binding commitments simplified and extended, with generalization to interpersonal allocation. Rationality and Society 2 (July): 287-309.

Strotz, R. H. 1956. Myopia and inconsistency in dynamic utility maximization. Review of Economic Studies 23:166-80.

Sugden, Robert. 1989. Spontaneous order. Journal of Economic Perspectives 3 (4): 85-97.

Thaler, Richard H., and H. M. Shefrin. 1981. An economic theory of self-control. Journal of Political Economy 89 (2): 392-406.

Winston, Gordon C. 1980. Addiction and backsliding: A theory of compulsive consumption. Journal of Economic Behavior and Organization 1:295-324. 